\title{
Consumption of legal and illegal cigarettes in the Gambia
}

\author{
Zunda Chisha ๑ , ${ }^{1}$ Mohammed L Janneh, ${ }^{2}$ Hana Ross $\odot{ }^{1}$
}

\begin{abstract}
- Additional material is published online only. To view please visit the journal online (http://dx.doi.org/10. 1136tobaccocontrol-2019055055).
\end{abstract}

${ }^{1}$ Economics of Tobacco Control Project, Southern African Labour and Development Research Unit, University of Cape Town, Cape Town, South Africa ${ }^{2}$ Ministry of Finance, The Gambia Bureau of Statistics, Banjul, Gambia

\section{Correspondence to} Zunda Chisha, Economics of Tobacco Control Project, Southern African Labour and Development Research Unit, University of Cape Town, Cape Town 7700, South Africa; zundac@gmail.com

Received 8 March 2019 Revised 24 April 2019

Accepted 26 April 2019 Published Online First 30 May 2019

\section{ABSTRACT}

Background The prevalence of cigarette smoking in the Gambia is relatively high, compared with most African countries. Little is known about the characteristics of the smokers and their habits, particularly with regard to tobacco tax avoidance and tax evasion.

Methods A nationally representative survey of 1211 smokers conducted in November/December 2017 employed a three-stage stratified sampling method and resulted in 1205 complete observations. The sociodemographic characteristics and smoking behaviours were analysed, including smoking intensity and brand preferences. Information on the physical features of cigarette packs that smokers had, observed by enumerators, and self-reported cigarette prices were used to estimate the proportion of illegal cigarettes on the market.

Findings As in many African countries, most smokers were male, between the ages of 25 and 54 years living primarily in urban areas. The three most popular cigarette brands are Piccadilly, Royal Business and Bond Street, which account for over three-quarters of all cigarette purchases. Price information suggests that about $7.3 \%$ of smokers purchased an illicit cigarette at their last purchase. When smoking intensity was taken into account, $8.6 \%$ of the total cigarette market was estimated to be illicit. Using an alternative method of evaluating pack's features revealed that only $0.9 \%$ of last purchases were illicit.

Conclusion Despite recent excise tobacco tax increases, the use of illicit cigarettes in the Gambia is low and does not represent a significant obstacle to reaching both the public health and fiscal goals of higher tobacco taxes.

\section{INTRODUCTION}

The Gambia is a West African country that is almost completely surrounded by Senegal, except for a narrow Atlantic coastline in the west. It has a population of about 2 million people, about $40 \%$ of whom are aged 15 years and under. ${ }^{1}$ Islam is the dominant religion, with approximately $90 \%$ of the population adhering to it. Smoking is relatively high. In 2013, adult daily smoking prevalence was estimated at $13 \%$, compared with just $7 \%$ in neighbouring Senegal. ${ }^{2}$ As in most African countries, current tobacco smoking prevalence is substantially higher among men than women (23\% among men compared with less than $1 \%$ among women). ${ }^{2-4}$

Tobacco use in the Gambia is more common among youths than among adults, particularly for girls. A 2017 study found that $25.7 \%$ of boys and 9.4\% of girls between the ages of 12 and 20 years had ever smoked cigarettes, cigars or pipes. ${ }^{3}$ Among these, manufactured cigarettes were the most widely used (57.7\%), compared with hand-rolled cigarettes (16\%), cigars (13.7\%) and pipes (12.6\%). All tobacco products are imported primarily from South Africa (49\%), Senegal (16\%), Nigeria (11\%), United Arab Emirates (UAE) (9\%), Switzerland $(8 \%)$ and Swaziland (6\%).

Prior to 2013, the Gambia had a single-tiered ad valorem tobacco tax system based on weight $(\mathrm{kg})$. This was changed to a specific excise tax system in 2013. An ad valorem tax is calculated as a proportion of the value of an item while a specific tax is a fixed charge for each unit of an item. ${ }^{2}$ According to the WHO, excise taxes accounted for $37.5 \%$ of the retail price of the most sold brand in the Gambia in 2016. ${ }^{2}$ Aside from excise taxes, other taxes levied on cigarettes include import duty, value-added tax, environmental tax, customs duty, an Economic Community of West African States (ECOWAS) levy and an African Union (AU) levy.

In addition to changing the tax structure, the Government of the Gambia began to increase the tax rate. The plan was to implement annual tobacco tax increases over a 3-year period (between 2014 and 2016) in order to get closer to the regional average price for sub-Saharan Africa per pack of cigarettes, about US\$1.24, equivalent to 38.86 Gambian dalasi (GMD), by 2016 (at 2012 prices). In 2016, building on the first series of increases, the country adopted another 3-year plan to increase the tax rate annually by GMD5 until 2019. ${ }^{2}$ The country's success in raising tobacco taxes and government revenue, while encouraging smoking reduction, ${ }^{2} 5$ was recognised by the 2017 WHO Director General's Award on World No Tobacco Day.

While tobacco taxation is arguably the most effective strategy to control tobacco use, its effect on the illicit tobacco trade is often debated. ${ }^{6}$ In many countries, the tobacco industry regularly claims that illicit trade is increasing as a result of higher tobacco taxes. ${ }^{78}$ The presence of an illicit cigarette trade could pose a serious threat to both public health and public finance by making cigarettes more affordable, counteracting restrictions on youth access, reducing government revenue and ultimately undercutting the ability of taxes to reduce consumption. ${ }^{9}$ On the other hand, the perpetual overstating of the role of tax in illicit trade by those opposed to higher tobacco taxes may distract from the tax's effectiveness as a policy tool.

To date, little is known of the magnitude of the illicit cigarette trade in many African countries, including the Gambia. This study investigates the use of both licit and illicit cigarettes in the Gambia using data from a nationally representative household survey conducted among smokers in 2017. It aims to overcome the weakness of previous surveys, 
which did not provide a detailed account of adult smoking behaviour, including the use of illegal products. The study also addresses the general paucity of nationally representative data on cigarette prices and brand preferences.

\section{DATA AND METHODS}

The nationally representative survey relied on a three-stage cluster randomised sample selection of adult smokers (aged 18 years and above) using the 2013 Population and Housing Census as the sampling frame. The Gambia is divided into eight local government areas (LGA), and then further subdivided into census enumeration areas (EA). The LGAs were used as geographical strata and the EAs were the primary sampling units. Our sample was taken from $134 \mathrm{EAs}$, out of a possible 4000 , proportionally selected across all LGAs, assuming a 95\% CI, 10\% margin of error, 95\% response rate, design effect of 1.6 and 66423 estimated number of households with a smoker. A selection of 20 households in each EA were interviewed, first using a household questionnaire to determine the presence of a smoker, and then subsequently using the individual questionnaire administered to a smoker. If there was more than one smoker in a household, one smoker was randomly selected from the eligible smokers listed on the household roster. Quality assurance was conducted by team leaders who reviewed forms completed by enumerators and by spot checks conducted by field coordinators. In addition, at data entry level, coders and entry clerks were supervised by staff of the Gambia Bureau of Statistics who also conducted the first round of data cleaning.

Weights are calculated as the inverse of the product of the selection probabilities of an EA, a household and an individual smoker within a household. The weights are then adjusted based on household and individual response rates. Response rates across LGAs are provided in table 1 of online supplementary material 1.

The data allowed us to explore the sociodemographic characteristics of individual smokers and their smoking behaviour, including smoking intensity, brand preference, source of cigarettes and, what, if any, other tobacco products they used. The prevalence of illegal cigarettes is estimated using two methodsan independent examination of the features of cigarette packs in the possession of smokers at the time of the interview, and a comparison of the self-reported unit price of a cigarette pack and the price of a legal pack.

\section{Criteria for illicit cigarettes}

According to the law, tobacco product packaging is expected to display one text message covering $30 \%$ of the front of the pack ('Smoking Kills') and another text message covering 30\% of the back of the pack ('Smoking Seriously Harms You and Others Around You'). ${ }^{10} \mathrm{~A}$ pack was also required to carry the wording 'Sold in The Gambia'.

During interviews, smokers were asked to show the pack of cigarettes they had purchased. Enumerators then examined these packs to determine the presence of the three statements. A pack that did not have all three required statements was considered illicit. Since not all smokers had a pack at the time of the interview, we study the difference between those with and without packs in the online supplementary material 1.

We also contract the self-reported cigarette purchase price with a minimum threshold price determined by the Gambia Revenue Authority (GRA), based on the 2017 tax law. The following levies and taxes are included in the legal price: excise tax (GMD20 per cigarette pack of 20$)$, import duty ( $20 \%$ of cost, insurance and freight (CIF)), value-added tax (15\% of CIF), environmental tax (GMD2.42 per pack of cigarettes), customs duty (1.55\% of CIF), an ECOWAS levy (1\% of CIF) and an AU levy $(0.2 \%$ of CIF). Based on these figures, the total tax per pack of cigarettes was estimated at GMD28.36 in 2017. It is reasonable to assume that all legal cigarettes would typically be sold for more than the sum of these taxes and levies. The threshold price was therefore set at GMD28.36 per pack-the minimum expected price per pack of 20 cigarettes of the cheapest brands on the market. Cigarette packs purchased below the minimum threshold price must have evaded paying taxes in the Gambia, because all purchases occurred in the Gambia.

\section{Estimating the cigarette market}

To arrive at an estimate of the relative size of the illicit cigarette market in the country, we first calculated unit prices of an individual cigarette stick by dividing the self-reported amount spent on the last purchase by the number of cigarettes bought. This was multiplied by 20 to get a standardised price for a pack of 20 cigarettes, the most common pack size. The number of cigarettes smoked per day was then multiplied by 365 (for daily smokers) and the number of cigarettes smoked per week by 52 (for some-day smokers) to obtain annual cigarette consumption. Dividing this amount by 20 gave the number of cigarette packs consumed by a smoker per year. The sum of these across all smokers constitutes the total cigarette market volume in packs for the sample.

Finally, the volume of the illicit cigarette market is obtained by restricting the sample to the smokers whose reported unit price per pack is below the threshold price. Dividing the volume of illicit cigarettes by the total volume of the cigarette market gives the illicit market share.

About $12.1 \%$ of the price observations had to be dropped, because it was not possible to determine whether the reported price was for a pack of 20 , a pack of 10 or a single cigarette stick. For the price analysis, therefore, the sample was restricted to only those observations that clearly captured the price of a single stick or a pack of 20 .

\section{RESULTS}

Table 1 presents the main demographic and socioeconomic characteristics of the respondents. As expected, most smokers interviewed were male (90.2\%). A larger proportion of smokers resided in urban areas (54.4\%), were married $(72.7 \%)$ and between the ages of 25 and 54 years (69.4\%). Most respondents came from Brikama (33.9\%), the largest of the LGAs, while the lowest number of respondents (3.1\%) was from the capital, Banjul. According to the 2013 census, Brikama accounted for $37.2 \%$ of the total population and Banjul accounted for only $1.7 \% .^{11}$

In terms of educational attainment, most respondents (41.4\%) reported having no schooling, $17.9 \%$ had some primary schooling and about a third (33.6\%) had completed at least secondary school (about 7\% did not provide information on education). In comparison, the Gambia Youth Report of 2013, which includes both smokers and non-smokers, found that about $32 \%$ of the youth had never been to school, $16 \%$ had attended only primary education and $47 \%$ had some level of secondary education. ${ }^{1}$ The discrepancies with our sample are due to the fact that the Youth Report of 2013 restricted the population to those between the ages of 13 and 30 years, while our sample focused on the adult smokers aged 18 years and above. 


\begin{tabular}{|c|c|c|}
\hline Variables & Unweighted, $n=1205$ & Weighted (\%)* \\
\hline \multicolumn{3}{|l|}{ Geographical area } \\
\hline Rural & 506 & 45.6 \\
\hline Urban & 699 & 54.4 \\
\hline \multicolumn{3}{|l|}{ Local government area } \\
\hline Brikama & 482 & 33.9 \\
\hline Kanifing & 270 & 22.6 \\
\hline Kerewan & 95 & 13.4 \\
\hline Janjanbureh & 101 & 6.0 \\
\hline Kuntaur & 81 & 6.6 \\
\hline Mansakonko & 55 & 3.8 \\
\hline Basse & 82 & 10.5 \\
\hline Banjul & 39 & 3.1 \\
\hline \multicolumn{3}{|l|}{ Gender } \\
\hline Female & 38 & 2.7 \\
\hline Male & 1076 & 90.2 \\
\hline \multicolumn{3}{|l|}{ Age category (years) } \\
\hline $18-24$ & 53 & 5.0 \\
\hline $25-34$ & 245 & 20.7 \\
\hline $35-44$ & 352 & 28.3 \\
\hline $45-54$ & 234 & 20.4 \\
\hline $55-64$ & 130 & 9.9 \\
\hline $65+$ & 92 & 7.7 \\
\hline \multicolumn{3}{|l|}{ Marital status } \\
\hline Single & 205 & 17.0 \\
\hline Married & 866 & 72.7 \\
\hline Divorced, widowed or separated & 46 & 3.3 \\
\hline \multicolumn{3}{|l|}{ Education } \\
\hline No schooling & 485 & 41.4 \\
\hline Some primary schooling & 197 & 17.9 \\
\hline Secondary school completed & 357 & 27.9 \\
\hline Postsecondary school completed & 77 & 5.7 \\
\hline \multicolumn{3}{|l|}{ Monthly income } \\
\hline Less than D1000 & 122 & 9.0 \\
\hline D1000-D2500 & 327 & 30.3 \\
\hline D2501-D5000 & 295 & 24.7 \\
\hline D5001-D10 000 & 116 & 9.2 \\
\hline Over D10 000 & 48 & 3.7 \\
\hline \multicolumn{3}{|l|}{ Type of tobacco used } \\
\hline Cigarettes & 856 & 70.8 \\
\hline Roll-your-own & 173 & 14.4 \\
\hline Other tobacco & 75 & 6.9 \\
\hline
\end{tabular}

* Percentages do not add up to 100 in some cases due to missing values on the following variables: gender-91 missing values; age category-99 missing values; marital status -1 prefer not to answer, 87 missing values; education -2 prefer not to answer, 85 missing values; monthly income -47 prefer not to answer, 250 missing values; type of tobacco used-101 missing values.

In terms of smoking behaviour, over $70.8 \%$ of tobacco users smoke cigarettes, $14.4 \%$ use roll-your-own (RYO) and $6.9 \%$ use other types of tobacco. This is similar to findings from the 2013 Demographic and Health Survey (DHS). ${ }^{12}$ Further, approximately $64.5 \%$ of all cigarette smokers reported buying single cigarette sticks compared with $8.1 \%$ who are purchasing a cigarette pack, the rest are missing. The analysis focuses only on those consuming manufactured cigarettes (table 2).

Most (95.7\%) cigarette smokers bought their cigarettes from a shop or store rather than from street vendors. Daily smoking intensity was estimated at 10.7 cigarettes smoked per day. This
Table 2 Preferences of cigarette users and cigarette prices $(n=856)$

\begin{tabular}{lcll}
\hline & $\begin{array}{l}\text { Unweighted } \\
\text { frequencies }\end{array}$ & $\begin{array}{l}\text { Weighted* } \\
(\%)\end{array}$ & $\begin{array}{l}\text { Mean price } \\
\text { (SD) }\end{array}$ \\
\hline $\begin{array}{l}\text { Place of purchase } \\
\quad \text { Store or shop }\end{array}$ & 820 & 95.7 & - \\
\hline $\begin{array}{l}\text { Street vendor } \\
\text { Smoker frequency }\end{array}$ & 27 & 2.8 & - \\
\hline Daily smoker & 796 & 93.6 & - \\
\hline Non-daily smoker & 57 & 5.9 & - \\
\hline Cigarette brand & & & \\
\hline Piccadilly & 277 & 32.6 & $57.18(15.81)$ \\
\hline Bond Street & 176 & 23.5 & $58.32(10.22)$ \\
\hline Royal Business & 217 & 23.6 & $40.77(7.83)$ \\
\hline Monte Carlo & 89 & 9.7 & $44.72(11.37)$ \\
\hline B\&H & 38 & 3.9 & $71.72(11.45)$ \\
\hline Sir & 18 & 2.8 & $38.61(43.29)$ \\
\hline Other brands & 27 & 2.3 & $36.78(24.93)$ \\
\hline
\end{tabular}

*Percentages do not add up to 100 in some cases due to missing values on the following variables: place of last purchase -9 missing values; smoker frequency-3 missing values; cigarette brand-14 missing values.

is quite similar to the 2013 DHS, which found that over $50 \%$ of cigarette smokers had smoked 10 or more cigarettes during the 24 hours preceding the survey. ${ }^{12}$

The three most frequently purchased cigarette brands were Piccadilly, Bond Street and Royal Business. Combined, these three brands account for $80 \%$ of all purchases. The remaining brand preferences are: Monte Carlo (10\%), Benson \& Hedges $(\mathrm{B} \& \mathrm{H} ; 3.4 \%)$ and Sir $(2.7 \%)$. The most expensive brand was B\&H at GMD71.72 (US\$1.51) per pack of 20, followed by Bond Street at GMD58.32 (US\$1.22) and Piccadilly at GMD57.18 (US\$1.20). The cheapest cigarette brand was Sir at GMD38.61 (US\$0.81) (see table 2).

In terms of illicit cigarette purchases, the survey found that approximately $7.3 \%$ of smokers may have recently purchased an illicit cigarette, based on the self-reported amount spent on the last purchase. However, when smoking intensity is considered, the market share of illegal cigarettes in the Gambia increases to $8.6 \%$ of the total market. This means that those evading cigarette taxes are heavier smokers. The estimate based on cigarette pack features is markedly different: only $0.9 \%$ of the packs examined were found without the requisite labels for a legal cigarette pack (see table 3). The brands identified without these labels were Piccadilly (one pack) and Monte Carlo (two packs).

We found statistically significant differences in pack possession across geographical areas, but also due to education (smokers with no schooling were less likely to have a pack), place of purchase (smokers buying at street vendors were less likely to have a pack) and smoking frequency (daily smokers were more likely to have a pack compared with occasional smokers). table 2 in online supplementary material 1 .

A sensitivity analysis conducted on the price threshold indicated more robustness moving downwards than it did moving upwards. We found the proportion of illicit cigarettes unchanged after varying the price threshold downwards by both $5 \%$ and $10 \%$, while it reduced to $7.9 \%$ when the price threshold was lowered by $15 \%$. In contrast, the proportion of illicit cigarettes remains unchanged when the price threshold was raised 5\% but jumped to $10.9 \%$ and $11.0 \%$ when the price threshold was raised $10 \%$ and $15 \%$, respectively. Further excluding occasional smokers from the sample does not change the estimate of the illicit market. 
Table 3 Proportion of smokers using illicit cigarettes in the Gambia

\begin{tabular}{lll}
\hline Proportion of self-reported purchases & $\begin{array}{l}\text { Unweighted, } \\
\mathbf{n}=812\end{array}$ & $\begin{array}{l}\text { Weighted } \\
(\%)\end{array}$ \\
\hline Above PT & 757 & 92.7 \\
\hline Below PT & 55 & 7.3 \\
\hline $\begin{array}{l}\text { Proportions of total market based on PT } \\
\text { Total cigarette consumption }\end{array}$ & 154752 & 100 \\
\hline Legal consumption & 141487 & 91.4 \\
\hline Illicit consumption & 13265 & 8.6 \\
\hline $\begin{array}{l}\text { Proportions based on cigarette pack features } \\
\text { Examined packs }\end{array}$ & 313 & 100 \\
\hline Legal cigarettes & 310 & 99.1 \\
\hline Illicit cigarettes & 3 & 0.9 \\
\hline
\end{tabular}

PT, price threshold (GMD28.36).

We compare the proportion of legal and illicit cigarettes disaggregated by sociodemographic characteristic and other variables in table 4. We found that those who were divorced, widowed or separated, older smokers, those with higher income and those buying from street vendors were more likely to use illicit cigarette.

Among illicit cigarettes determined using only the price threshold, Piccadilly accounted for $32.7 \%$ of illicit cigarettes, Monte Carlo for 13.5\%, while Force 10 and Royal Business accounted for $11.5 \%$ each. Bond Street and Sir accounted for $9.6 \%$ of the illicit market each while D\&J accounted for 7.7\% of the illicit market (see figure 1). The lowest share of illicit cigarettes was held by the brands Ransom and $\mathrm{B} \& \mathrm{H}$, which each accounted for $1.9 \%$.

Given that the overall market shares of Piccadilly (32.6\%) and Monte Carlo (10\%) are close to their illicit market shares, these brands seem to be supplied almost evenly via both channels. On the other hand, the overall market share of Royal Business $(24.5 \%)$ is much higher compared with its illicit market share, meaning that this brand is primarily supplied legally. Brand Force 10 seems to be supplied almost exclusively via illegal channels.

\section{DISCUSSION}

Tobacco control efforts in the Gambia have been accelerating following the implementation of prohealth tobacco tax policies in 2014. ${ }^{13}$ This study examines the sociodemographic profile of cigarette consumption in the Gambia based on data from a nationally representative survey. We also provide estimates of illicit cigarette consumption using specified criteria for price and cigarette pack characteristics.

Most smokers in the Gambia are daily smokers below the age of 55 years. Tobacco use is almost entirely a male activity with only $2.7 \%$ of the sample of smokers being women. Consistent with the literature, ${ }^{2}$ consumption of other tobacco products such as RYO, cigars and cheroots is less prevalent (only $14.4 \%$ of RYO users and $6.2 \%$ of users of other tobacco products among the sample of smokers).

Comparing the results to an earlier study based on 2012 data, ${ }^{13}$ we found that Monte Carlo ceded the largest market share to Piccadilly, Royal Business and Bond Street. Piccadilly leads the market despite being about $40 \%$ more expensive than the next most popular brand, Royal Business. The shift in market shares is reflected in changes in the value of imports from different countries of origin. According to information from the GRA, imports from Swaziland, where Monte Carlo originates, fell 9\% between 2012 and 2017, while imports from the UAE (home of Royal Business) fell only $3 \%$. In contrast, imports from South Africa
Table 4 Proportion of illicit cigarettes by sociodemographic characteristics

\begin{tabular}{|c|c|c|}
\hline & Illicit (\%) & $P$ value \\
\hline \multicolumn{3}{|l|}{ Local government area } \\
\hline Banjul & 7.4 & 0.9904 \\
\hline Kanifing & 5.7 & \\
\hline Brikama & 6.5 & \\
\hline Mansakonko & 6.1 & \\
\hline Kerewan & 4.2 & \\
\hline Kuntaur & 2.9 & \\
\hline Janjanbureh & 6.5 & \\
\hline Basse & 5.7 & \\
\hline \multicolumn{3}{|l|}{ Geographical area } \\
\hline Urban & 6.4 & 0.4687 \\
\hline Rural & 5.1 & \\
\hline \multicolumn{3}{|l|}{ Gender } \\
\hline Male & 5.8 & 0.1111 \\
\hline Female & 19.2 & \\
\hline \multicolumn{3}{|l|}{ Age category (years) } \\
\hline $18-24$ & 1.9 & $0.0259^{* *}$ \\
\hline $25-34$ & 4.7 & \\
\hline $35-44$ & 5.3 & \\
\hline $45-54$ & 4.9 & \\
\hline $55-64$ & 12.4 & \\
\hline $65+$ & 16.6 & \\
\hline \multicolumn{3}{|l|}{ Marital status } \\
\hline Single & 3.2 & $0.0714^{*}$ \\
\hline Married & 6.8 & \\
\hline Divorced, widowed or separated & 11.4 & \\
\hline \multicolumn{3}{|l|}{ Education } \\
\hline No schooling & 7.5 & 0.4982 \\
\hline Some primary schooling & 3.8 & \\
\hline Secondary school completed & 5.6 & \\
\hline Postsecondary school completed & 5.8 & \\
\hline \multicolumn{3}{|l|}{ Monthly income } \\
\hline Less than D1000 & 5.8 & $0.0217^{* *}$ \\
\hline D1000-D2500 & 3.9 & \\
\hline D2501-D5000 & 8.7 & \\
\hline D5001-D10 000 & 2.3 & \\
\hline Over D10 000 & 16.2 & \\
\hline \multicolumn{3}{|l|}{ Place of purchase } \\
\hline Store or shop & 5.2 & $0.0001 * * *$ \\
\hline Street vendor & 28.6 & \\
\hline \multicolumn{3}{|l|}{ Smoker frequency } \\
\hline Daily smoker & 5.8 & 0.7734 \\
\hline Non-daily smoker & 7.3 & \\
\hline
\end{tabular}

We conclude that there is a statistically significant difference among the respective category groups for ${ }^{*} \mathrm{p}<0.10$; ${ }^{* *} \mathrm{p}<0.05 ;{ }^{* * *} \mathrm{p}<0.01$.

(home of Piccadilly) rose $27 \%$ over the same period. Imports from Senegal and Switzerland (both origin countries for Bond Street) fell $23 \%$ and $6 \%$, respectively, over the same period.

Findings on the consumption of illicit cigarettes suggest a very low prevalence. Of the smokers interviewed, $7.3 \%$ reported prices of their last purchase that were below the total amount of applicable tax for a pack of cigarettes. Based on this, illicit cigarettes constitute about $8.6 \%$ of the total market base while only $0.9 \%$ of the cigarette packs in the possession of smokers did not comply with the labelling requirements and were classified as illicit. The difference between the two estimates can be 


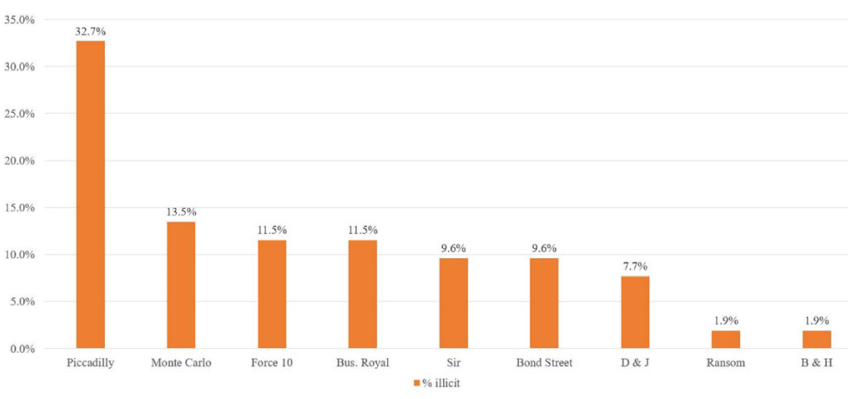

Figure 1 Proportion of brands of illicit cigarettes.

explained by the type of tax evasion captured by each method. ${ }^{14}$ The reported price method captures the likely proportion of legally manufactured cigarettes not declared to customs (thus not paying taxes), while the package method estimates the proportion of potentially counterfeit or smuggled cigarettes from other countries.

Smokers who consume illegal cigarettes are older, have higher income, are divorced, widowed or separated and buy their cigarettes from street vendors. This is similar to some results in the USA, ${ }^{15} 16$ where smokers with higher incomes were also more likely to report purchasing illegal cigarettes. This was explained by a minimum level of resources needed to search for better prices.

Several brands were identified among the illicit cigarettes, but Piccadilly, Monte Carlo and Force 10 brands accounted for more than half of them. Interestingly, Piccadilly and Monte Carlo brands came up as possibly illicit using both the price criteria and the pack examination criteria. Other illicit brands were Bond Street, Royal Business, Sir, D\&J, Ransom and B\&H, all classified as illicit based on the price criteria. Anecdotally, we learnt that the GRA conducted an enforcement exercise in early 2019 that resulted in the seizure of illicit cigarettes from local supermarkets. Among the brands seized were Monte Carlo, Royal Business and Sir, all of which were supplied by one importer in trucks via Mali. Both Royal Business and Sir originate from the UAE, a known source country for 'illicit whites'.917

The study has two main strengths. First, it provides the first nationally representative estimates of illicit cigarette consumption in the Gambia. Second, the use of two complementary methods of estimation reduces the weaknesses of any one method. For instance, the popularity of single cigarette stick sales (thus low cigarette packs available for examination) implies that the estimate of illicit cigarettes based on examined packs may be biased if the form of purchase is correlated with the likelihood of buying illegal cigarettes. Both estimates are, however, indicative of low illicit cigarette consumption.

Cross-border shopping is not likely to be an issue for the Gambia, since neighbouring Senegal has historically had higher cigarette prices. Only recently have the Gambia's efforts to raise tobacco taxes reversed the price difference between the two countries: the most sold brand in the Gambia in 2017 was priced higher (US\$0.96) than its equivalent in Senegal (US\$0.85). ${ }^{18}$ Despite this price difference, and the recent considerable tax increases, the size of the illicit market in the Gambia is small.

The study has some limitations: First, given the negative social perception of smoking in the Gambia, the study may have missed some households with a smoker. Second, the lack of prior nationally representative survey of smokers means that the sampling frame could not be designed to select a representative sample of smokers. However, the results conform to our expectations of a higher smoking prevalence among men and a higher consumption of cigarettes than of other types of tobacco. The sample is also compatible with the overall demographic and socioeconomic characteristics of the population revealed by the Gambian 2013 census. These give us confidence in the validity of our results.

Third, many smokers purchase single cigarette sticks and thus do not have a pack to be examined during the survey. The very low number of examined packs (only about a quarter of smokers interviewed had a cigarette pack at home) suggests that the sale of single sticks is a relatively common practice. Our approach mitigates this limitation by using the price threshold criteria for determining illicit cigarette purchases as well as the pack examination method. Although the proportions estimated by the two methods differ, reflecting the likely type of illicit cigarettes captured, the overall conclusion is unanimous-the size of the illicit cigarette market in the Gambia is low compared with the markets in other African countries such as South Africa (about $30 \%)^{19}$ and Kenya (about 26\%). ${ }^{20}$

Finally, the self-reported prices may suffer from a recall bias. Since the majority (90\%) of our sample consists of daily smokers, we believe that such bias will be limited. Additional concerns regarding the restriction of the analysis to manufactured cigarettes are also noted. This inherently precludes any conclusions about the tax evasion among other tobacco products such as RYO or shisha. Shisha, for instance, appears to be increasingly popular among the youth in the Gambia ${ }^{3}$ and warrants further investigation, but lies beyond the scope of this study.

In conclusion, the Gambia's attempts to improve public health with respect to cigarette consumption have been largely successful and well documented. However, the most recent 3-year goal to increase excise taxes to GMD30 per pack by 2019 is likely to be missed as the current excise tax amounts to only GMD25 per pack. We recommend the government raise the tax on tobacco products to meet this target and even surpass it, as it is evident from our findings that illicit cigarette consumption is relatively low in the Gambia, posing no significant risk to achieving lower smoking prevalence and higher tax revenue. However, it is still important to monitor the size of illicit market over time, particularly with respect to the brands identified as illicit in this study. The Gambia also needs to enhance law enforcement in the area of tobacco control and cooperate with Senegal and other sub-Saharan countries to combat the supply of illegal tobacco products in order to maximise the impact of higher taxes on public health gains.

What this paper adds

Most recent sociodemographic descriptions of adult smokers in the Gambia, a West African State.

- An analysis of cigarette prices and brands across geographic regions of the Gambia.

- The first estimates of the prevalence of illicit cigarette use in the Gambia, based on prices and cigarette pack characteristics.

Acknowledgements The authors acknowledge and thank all data collectors, survey supervisors and managers at the Gambia Bureau of Statistics (GBOS) for their contribution to this study. The authors also thank Professor J Michael Bowling, University of North Carolina at Chapel Hill, for his invaluable guidance on the sampling and weight calculations adopted in this study.

Contributors HR conceptualised the research. $\mathrm{ZC}$ and $\mathrm{MLJ}$ designed the questionnaires with input from HR. MLJ managed the project in the Gambia and coordinated the data collection. ZC analysed the data. The results were synthesised 
and written by ZC and HR, with inputs from MLJ. All authors read and approved the final manuscript.

Funding The funding for this study came from the Cancer Research UK (IRMA number 30845).

Competing interests None declared.

Patient consent for publication Not required.

Provenance and peer review Not commissioned; externally peer reviewed.

Data sharing statement Data are available upon reasonable request.

\section{ORCID iDs}

Zunda Chisha http://orcid.org/0000-0001-9113-8555

Hana Ross http://orcid.org/0000-0001-5799-1915

\section{REFERENCES}

1 Gambia Bureau of Statistics, Republic of The Gambia. Population and housing census 2013: the youth report 2013.

2 WHO. Who report on the global tobacco epidemic, 2017. World Health Organization, 2017.

3 Jallow IK, Britton J, Langley T. Prevalence and determinants of tobacco use among young people in the Gambia. BMJ Glob Health 2017;2:e000482.

4 Winkler V, Lan Y, Becher H. Tobacco prevention policies in west-African countries and their effects on smoking prevalence. BMC Public Health 2015;15.

5 World Health Organization. Who report on the global tobacco epidemic, 2013: enforcing bans on tobacco advertising, promotion and sponsorship. World Health Organization, 2013.

6 Smith KE, Savell E, Gilmore AB. What is known about tobacco industry efforts to influence tobacco Tax? A systematic review of empirical studies. Tob Control 2013:22:e1.
7 Gilmore AB, Fooks G, Drope J, et al. Exposing and addressing tobacco industry conduct in low-income and middle-income countries. The Lancet 2015;385:1029-43.

8 Rowell A, Evans-Reeves K, Gilmore AB. Tobacco industry manipulation of data on and press coverage of the illicit tobacco Trade in the UK. Tob Control 2014;23:e35-43.

9 Joossens L, Raw M. From cigarette smuggling to illicit tobacco trade: table 1. Tob Control 2012;21:230-4.

10 Campaign for Tobacco-Free Kids. Legislation by country: Gambia. Campaign for Tobacco-Free Kids 2017

11 The Gambia Bureau of Statistics. Gambia rot. The Gambia 2013 population and housing census preliminary results.

12 The Gambia Bureau of Statistics - GBOS, ICF International. The Gambia demographic and Health survey 2013. Banjul, The Gambia: GBOS and ICF International, 2014.

13 Nargis N, Manneh Y, Krubally B, et al. How effective has tobacco Tax increase been in the Gambia? A case study of tobacco control. BMJ Open 2016;6:e010413.

14 Ross H. Understanding and measuring cigarette Tax avoidance and evasion: a methodological guide. Tobacconomics 2015.

15 Fix BV, Hyland A, O'Connor RJ, et al. A novel approach to estimating the prevalence of untaxed cigarettes in the USA: findings from the 2009 and 2010 international tobacco control surveys. Tob Control 2014;23(suppl 1):i61-6.

16 Hyland A, Bauer JE, Li Q, et al. Higher cigarette prices influence cigarette purchase patterns. Tob Control 2005; 14:86-92.

17 Ross H, Vellios N, Clegg Smith K, et al. A closer look at 'Cheap White' cigarettes. Tob Control 2016;25:527-31.

18 WHO. WHO Report on The Global Tobacco Epidemic, 2017. In: Tobacco free initiative, 2017.

19 Van der Zee K, Magadla S, Van Walbeek C. An analysis of cheap cigarettes in South Africa. 2019.

20 Ross H. Tracking and tracing tobacco products in Kenya. Prev Med 2017;105:S15-8. 